\title{
Innovative approach to University clinics positioning in sustainable economic development concept in conditions of changing challenges
}

\author{
Natalia Kubina*, Dmitry Kashparov, Lyudmila Puryzhova, and Irina Kravchenko \\ Immanuel Kant Baltic Federal University, Russia
}

\begin{abstract}
The issues related to the development of university medicine in connection with the emerging epidemiological situation and trends for the future are becoming more and more relevant in both research and practical aspects all over the world. The experience of university clinics abroad has been sufficiently studied, however, in Russia, the process of formation and development of medical clinics at leading Federal Universities has begun recently, and is not active enough. Currently, there are no more than 10 university clinics in the country, their experience, functioning mechanisms and contribution to the general results of a healthcare development has not yet been summarized and described in the scientific literature. At the same time, the scientific description and study of the issues of University clinics as medical institutions of a special type capable of providing high-tech medical services to the population and solving the issues of human resources for developing medicine are very relevant and significant in implementing the sustainable economic development concept in the conditions of changing challenges. Based on the analysis of the experience of foreign University clinics, an attempt is made to study the model and generalize the experience of University clinics formation in Russia in order to identify the main problems and prospects for their development. Without pretending to cover the whole range of problems associated with the development of university medicine, the main objective of the study is the issues of an innovative approach to the formation concept of medical centers positioning on the platform of a "University Clinic" brand. Using the example of the University Clinic - Clinical and Diagnostic Center of Immanuel Kant Baltic Federal University (CDC IKBFU) the process of forming the concept of University clinic positioning was described; a situational analysis of the medical services market was carried out in order to identify the problems in sustainable growth goal-setting; possible approaches to the choice of the positioning concept of the University Clinic were analyzed; the concept of the CDC positioning on the platform of the "University Clinic" brand was proposed; a model of a "pyramid of values" was built for a medical organization of this type; an innovative approach to the formation of the clinic's media policy was proposed; the recommendations were developed to implement the concept of the platform of the "University Clinic" brand positioning in the online
\end{abstract}

\footnotetext{
*Corresponding author: nkubina@kantiana.ru
} 
environment in the information openness context. The findings obtained make it possible to continue the study of a whole range of issues, both scientific, methodological and practical, concerning the substantiation of an effective model for University clinics functioning; solving organizational, managerial and legislative aspects related to their departmental subordination, coordination of the ministries of education and healthcare, the sources of their funding, the forms of state support and others.

\section{Introduction}

The changing conditions of existence and recent challenges have contributed to the fact that the issues of medical care have become one of the most discussed in the world, both from the standpoint of scientific medical research and the organization and efficiency of providing medical services to the population. The healthcare systems of individual countries were formed and developed in different ways, each of them has its own characteristics, but the need for change has affected each of them. The development of Russian healthcare is characterized by a variety of approaches applied in order to manage and organize the medical care provision, and at the same time, by an integrated approach based on the application of market mechanisms with the state retaining the right to manage healthcare facilities. Maintenance of the population, health and well-being of people are defined as one of the main goals of sustainable development in 2015 in the framework of the 2030 agenda of the UN and also the Russian Federation for the period up to 2030 [1, 2, 3], which is caused by the current demographic situation due to persistent deterioration of human health, dissatisfaction with the quality and unavailability of high-tech medical care, limited state guarantees of free medical care. In order to achieve the goal set for maintaining the population and improving people's health, a significant role is played by medical institutions of a special type, University clinics, which possess highly qualified personnel, high-tech medical equipment, and modern methods of providing medical care.

In Russia, since 2012, the formation and development process of University clinics at the leading Federal universities of the country has begun. However, this process is not active enough, currently, there are no more than 10 university clinics in the country [4], their role, functioning mechanisms and contribution to the overall result of healthcare have not yet clearly defined. The discussion of models for developing university medicine is a very topical issue, but has not yet received proper coverage both in the scientific literature and in real practice. The issues of company brand positioning, goods and territories have been covered in sufficient detail in the scientific literature $[5,6]$, but they do not relate to the University clinics positioning. Meanwhile, the concept development and competent positioning of a University Clinic as a medical organization of a special type will allow, in our opinion, to solve a number of problems: to create an appropriate image among the medical community, to solve, to a large extent, the problem of the availability of high-tech medical care to the local population without leaving the territory, will contribute to the fact that the University Clinic will be the core for creating medical clusters in the regions. The above-mentioned aspects make the stated research very relevant.

The subject of the study is the University Clinic (Clinical and Diagnostic Center of Immanuel Kant Baltic Federal University - CDC IKBFU). The purpose of the research is to develop a concept for the CDC positioning on the platform of the "University Clinic" brand. Within the framework of the set goal, the following tasks were solved during the research:

-the situational analysis of the medical services market, identification of the problems in sustainable development goal-setting until 2030; 
- research of the experience of forming and developing university clinics in Russia and abroad;

- analysis of possible approaches to the choice of the concept of University clinics positioning as medical institutions of a special type;

- development of the concept of the CDC positioning on the platform of the "University Clinic" brand, building a model of the "brand value pyramid";

- development of the recommendations for implementing the concept of positioning the "University Clinic" brand in the online environment in the information openness context.

\section{Materials and research methods}

The research methodology is built in accordance with achieving the main goal of the studythe formation concept of medical centres positioning on the platform of the "University Clinic" brand in the context of changing challenges.

The study includes a content analysis of sources that characterize the current scientific and practical state of the formation and development of university clinics in Russia and abroad. The Clinical Diagnostic Center of Immanuel Kant Federal University (CDC IKBFU) in the Kaliningrad region was selected as a detailed subject of the study. The authors conducted a study of the medical services market in the region and assessed the competitive position of CDC in June - August 2020, analyzed the media policy of CDC, conducted surveys of the population and medical personnel in the region in order to assess the recognition of CDC, its perception, satisfaction with the quality of services provided and availability of high-tech medical services in the region.

The research was based on the analysis of scientific publications on the topic, methods of comparative and problem-target analysis of statistical indicators of the medical services market, as well as benchmarking that allows to study the best practices of foreign and Russian university clinics and take it into account when developing recommendations for the selected subject of analysis - CDC IKBFU. In order to assess the positioning indicators of medical centres, the online analytics service of the SimilarWeb website was used.

\section{Results and discussion}

\subsection{Situational analysis of medical services market, identification of problems in sustainable economic development goal-setting 2030}

Modern challenges are making changes to the development of all sectors of the economy, including healthcare. The volume of the medical services market fluctuates under the influence of a number of factors associated with both negative changes in the external environment, in particular a pandemic, an increase in the incidence of the population caused by a deteriorating environmental situation, and, on the other hand, with the biomedical technologies development, changes in behavior patterns and public attitude to health $[7,8]$ Therefore, this is the situational analysis of the industry market that should start with while developing the strategy for medical institutions, including University clinics, the formation of the positioning concept in the context of high market volatility and increasing competition.

According to the Federal State Statistics Service, in the period from 2015 to 2019, the number of medical organizations in the Russian Federation increased by $8 \%$, reaching 46.8 thousand in December 2019 (Table 1), and the growth in the number of employees of medical institutions in 2019 compared to 2018 amounted for $1.1 \%$. [9, 10] 
Table 1. The number of medical organizations and personnel in the Russian Federation in 2015-2019.

\begin{tabular}{|l|c|c|c|c|c|}
\hline \multicolumn{1}{|c|}{ Parameter } & $\mathbf{2 0 1 5}$ & $\mathbf{2 0 1 6}$ & $\mathbf{2 0 1 7}$ & $\mathbf{2 0 1 8}$ & $\mathbf{2 0 1 9}$ \\
\hline $\begin{array}{l}\text { The number of } \\
\text { medical organizations } \\
\text { ((thousand units) }\end{array}$ & 43,3 & 45,2 & 44,9 & 46,8 & 46,8 \\
\hline $\begin{array}{l}\text { The number of } \\
\text { personnel in medical } \\
\text { organizations } \\
\text { (thousand people) }\end{array}$ & 3629,8 & 3633,1 & 3520,7 & 3588,9 & 3628,6 \\
\hline
\end{tabular}

The growth in the number of medical organizations and personnel contributed to an increase in the indicators of the number of medical services provided for the analyzed period: in 2019, the indicator of the number of medical services provided amounted to 1,132 million appointments, which is $2.7 \%$ more than in the base year 2015 .

The analyzed period was also characterized by an increase in morbidity. In 2019, 162.8 thousand cases of morbidity were recorded, (Table 2) the basic growth index of this indicator for 2015-2019. showed an increase of $1.7 \%$ [9, 10].

Table 2. Morbidity of population, RF, 2015-2019. (cases per 100 thousand people).

\begin{tabular}{|l|c|c|c|c|c|}
\hline \multicolumn{1}{|c|}{ Parameter } & $\mathbf{2 0 1 5}$ & $\mathbf{2 0 1 6}$ & $\mathbf{2 0 1 7}$ & $\mathbf{2 0 1 8}$ & $\mathbf{2 0 1 9}$ \\
\hline $\begin{array}{l}\text { Morbidity of population } \\
\text { (cases per 100 thousand } \\
\text { people) }\end{array}$ & 160056,1 & 161628,4 & 161776,0 & 162644,5 & 162793,0 \\
\hline \% to the previous year & - & 0,98 & 0,09 & 0,54 & 0,09 \\
\hline
\end{tabular}

According to BusinesStat estimates, in 2020, due to the growth of coronavirus infection in the cities of the Russian Federation, the number of which exceeds 100 thousand people, the chain volume growth index of the medical services market amounted to $106.5 \%$. According to the experts, in 2021 the situation with the pandemic will stabilize and, in this regard, the market volume will amount to 794.2 million appointments (Fig. 1.). According to the forecasts, by 2024 the number of medical appointments provided in cities of the Russian Federation with the population of more than 100 thousand people will have reached 1,148 million, which will exceed the value of the base index in 2021 by more than $40 \%$. [11]

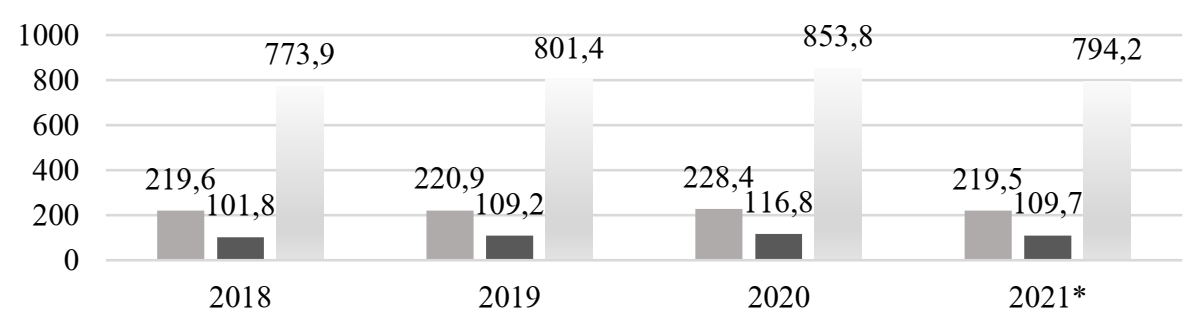

$\square$ Moscow $\square$ Saint-Petersburg - Other cities with population more than 100,000 people

Fig. 1. The volume of medical market in Russian cities with more than 100 thousand inhabitants, 2018-2021 (mln appointments) [12].

The volume of the market for fee-paying healthcare services has also been growing over the past 10 years. In 2019, this figure was 846.5 billion rubles, which is $30 \%$ higher than in 2009.

In the Kaliningrad region, according to the Ministry of Healthcare, as of 01.01.2019, 122 state, municipal and departmental medical organizations operating in the field of 
obligatory health insurance were registered. Of these, the bulk is concentrated in the regional centre, in Kaliningrad [13]. The market structure: the ratio of public and private medical institutions in the region is $30 \%$ and $70 \%$, respectively. The market fee-paying healthcare services in the region is quite developed and is represented by multidisciplinary clinics (Edkar, Klass Klinik, Medexpert, MC April, etc.), specialized clinics (Phlebology center, Kaliningrad Mammological Centre, MasterSlukh medical center and others), the federal independent laboratories (Gemotest "," Invitro "," Helix "," Citylab "," Genomed ","Evidence-Based Medicine Centre"), dental and cosmetic clinics, medical centers of alternative medicine. Within the framework of IKBFU. since 2012 the University Clinic, the Clinical Diagnostic Centre (CDC) has been functioning. A comparative analysis of the medical services market in the Russian Federation, the Northwestern Federal District (NWFD) and the Kaliningrad region [13] revealed a number of problems that need to be addressed:

- provision with doctors in the region (Table 3):

Table 3. Provision of doctors for the period 2017-2018 (per 10,000 of the relevant population).

\begin{tabular}{|l|c|c|c|}
\hline \multicolumn{1}{|c|}{ Parameter } & $\mathbf{2 0 1 7}$ & $\mathbf{2 0 1 8}$ & $\mathbf{2 0 1 8}$ in \% to 2017 \\
\hline $\begin{array}{l}\text { Provision of doctors per 10,000 of the relevant } \\
\text { population }\end{array}$ & 37,3 & 37,4 & 0,3 \\
\hline $\begin{array}{l}\text { Provision of doctors per 10,000 of the relevant } \\
\text { population of the Northwestern Federal } \\
\text { District (NWFD) }\end{array}$ & 42,8 & 43,1 & 0,7 \\
\hline $\begin{array}{l}\text { Provision of doctors per 10,000 of the relevant } \\
\text { population of the Kaliningrad region }\end{array}$ & 29,9 & 30,4 & 1,6 \\
\hline
\end{tabular}

Source: Compiled by the authors.[13]

As can be seen from the data in Table 3, the provision of doctors in the Kaliningrad region is lower than this indicator both in the Russian Federation as a whole and in the Northwestern Federal District. The growth of this indicator for the year by $1.6 \%$ is positive.

- the hospital stay length per a patient. The average hospital bed-occupancy per year (in days) is $5.7 \%$ higher than the average for the Russian Federation, in the Kaliningrad region, it amounted to 333 days in 2018 , which exceeds the same indicator for NWFD by $2.8 \%$ [ $10,13]$.

- the level of indicators for socially significant diseases. The analysis of the incidence dynamics of the population in the Kaliningrad region shows that the incidence in a number of areas is significantly higher than the average Russian indicators, higher than in NWFD, and for the period 2015-2019, the growth rate is increasing. [13]. For example, for tuberculosis: the number of patients under dispensary supervision at the end of 2018 per 10,000 of the relevant population averaged 56.0 people in NWFD, and 65.7 people in the Kaliningrad region. The incidence of malignant neoplasms at the age of 0-17 years per 10,000 of the relevant population on average in the Russian Federation is 12.9 people, in NWFD - 14.7 people, and in the Kaliningrad region - 20.7 people, while malignant neoplasms of lymphatic and hematopoietic tissue -11.4 people per 10,000 population of the region, which is two times higher than in the Russian Federation and higher than in NWFD - 6.9 people. $[10,13]$.

- dissatisfaction with the quality of medical services provided: only $32 \%$ of the residents are satisfied with the quality of services received in medical organizations in Kaliningrad and the region. [14].

- the problem of population's distrust, the belief that there is no high-tech medical care in the region, and that it is necessary to apply for the clinics in the capital or abroad. The surveys have shown that $38.7 \%$ of the residents in the region believe that in "difficult 
cases" it is better to try to apply for medical care in Moscow and St. Petersburg or in the neighbouring countries (Belarus, Lithuania, Poland, Germany). [14]. .

In accordance with the sustainable development concept and the achievement of sustainable development goal-setting until 2030, it is necessary to form a healthcare system that ensures the availability of high-quality and high-tech medical care, the volumes, types and quality of which should correspond to the level of morbidity and the needs of the population and the advanced achievements of medical science. Achieving the set goals within the specified time frame and solving a set of designated tasks require the discussion of not only specific medical problems, but also innovative approaches to the healthcare system management processes, the formation of medical clusters in regions, the core of which may become medical institutions of a special type - University clinics of leading Federal universities.

\subsection{Analysis of formation and development experience of University clinics as medical organizations of special type, capable of providing high-tech medical services to population and contributing to economic growth}

The issues of researching the role of University clinics in the sustainable economic development system, organizing their activities as centres for providing high-tech medical services to the population, positioning and promoting them with the help of modern communication tools in the digital environment have not yet received due attention both from scientific research and from studying and summarizing the experience of the best world practices in this area.

The fundamental difference between a University clinic as one of the links in the healthcare system from other types of medical and preventive organizations is the combination of serious fundamental training of specialists and the application of the most advanced medical technologies and equipment in treatment practice. As the study of foreign experience shows, the model of functioning of university clinics is very popular and cost effective. In the countries of the European Union and the USA, leading universities have their own clinics. The educational process in them is inextricably linked with research, development and implementation of new medical technologies. Typically, university hospitals are the best in their country, many of which are well known throughout the world. $[15,16,17,18,19,20,21,22]$. At present, about 40 such organizations are successfully operating in Germany. They serve about 1.7 million patients from all over the world annually. Taking into account state funding, and this fact must be taken into account, the medical activity of university clinics is very profitable. 32 university hospitals generate revenues of around 13 billion euros annually. The most successful clinic, from a scientific, educational and economic point of view, is the Charite University Medical Complex in Berlin, which is the educational and scientific base of Humboldt University and the Free University in Berlin. Here, on average, 139 thousand patients are treated per year in hospitals and 593 thousand on an outpatient basis, 7 thousand operations are performed per month, 4.7 thousand deliveries per year, 700 transplants per year. At the same time, the average hospital bed-occupancy per day is about six days. The annual turnover of the complex is more than 1.3 billion euros. The clinics are located in all federal states, covering all regions of the country, the University Clinic creates conditions for scientific and practical activities of lecturers and students [15]. In France, university hospital centres, Centers Hospitaliers Universitaires (CHU) are successfully operating. They contain a single network throughout the country, uniting 32 medical institutions, and represent either a division of the university, or an independent institution associated with a legal agreement [16]. UK University Hospitals (Teaching Hospitals) are part of the National Health Service, run by Acute Trusts and are clinical bases for medical universities and schools, providing 
medical practice for students. In addition, some Acute Trusts are regional or national centers for providing specialized and high-tech medical care [17]. There are more than a thousand university clinics in the United States, of which 400 are on the Council of Teaching Hospitals and Health Systems (COTH). On the basis of the clinics, more than 75 thousand doctors from the USA and other countries are trained annually [18]. In Israel, there are such well-known medical centres as the Ber-Sheva University Hospital, Soroka University Medical Centre, where doctors combine medical, educational and scientific activities, and the Hadassah Clinic, which belongs to the clinic of the Jewish University in Jerusalem, provides medical services to more than one million people a year. More than half of Israel scientific research is conducted here [19, 20]. The closest neighbours of the Kaliningrad region, the Baltic states, also have positive experience in setting up university clinics. Vilnius University Hospital Santariškių klinikos is a medical institution of Vilnius University, where vascular reconstructive surgery, endovascular surgery, medical genetics, sports medicine and rehabilitation are prioritized. The university clinic employs 350 doctors of medical sciences, annually about 85 thousand patients are treated in the hospital, more than 30 thousand various operations are performed, 800,000 patients are served in outpatient departments. The only university hospital in Estonia is the University of Tartu Hospital (Tartu Ülikooli Kliinikum). Outpatient care is provided annually to 420 thousand patients, inpatient care to 45 thousand patients, about 20 thousand operations are performed per year, including kidney, bone marrow, liver and lung transplantation [21, 22].

Let us consider the situation with the formation and development of University clinics in Russia. Medicine in Russia has traditionally been formed on the clinical basis. However, in the perestroika years, the system of close connection between education and practice in healthcare was largely lost. Currently, the process of recreation of University clinics is underway, but the clinical medicine development on the basis of the country's leading universities is not yet widespread: there are no more than 10 University clinics in the country, which have adopted the main principle of world medical education - from the student audience to a patient's bed. ... The pioneers in this process were Medical Scientific and Educational Centre in Lomonosov Moscow State University (MSEC LMSU), which was commissioned in December 2013, and the Medical Center of Far Eastern Federal University (FEFU). MSEC occupies about 60 thousand square meters and includes a hospital with 8 surgical rooms and departments with a capacity of 300 beds, a polyclinic for 320 visits per day, a laboratory and research building, an educational building with equipped auditoriums and a conference hall for 220 seats. The clinic is multidisciplinary with an outpatient diagnostic focus. [23]. Pirogov High Medical Technology Clinic (polyclinic, hospital) of St. Petersburg State University is the leading multidisciplinary medical, scientific and educational institution in Russia. Every year, more than 20 thousand patients receive medical care in this clinic, the main focus being surgical activity. The average length of hospital bed-occupancy is decreasing and is currently 3.9 days. The preoperative period in various departments is on average 1.6 to 0.6 days, and the postoperative period is from 4.7 to 1.5 days. More than half of the patients are residents from other regions of Russia. The attraction of nonresident patients is mainly due to the doctors' out-reach consultations. In the regions of Russia, advisory services are provided to more than 3 thousand patients per year, of which more than half require surgical treatment, which they are provided with on the basis of the clinic. The clinic employs 280 doctors, including 20 Doctors of Medicine and Biological Sciences, $70 \mathrm{PhDs}$ in Medicine. The clinic is certified according to the quality management system ISO 9001-2015 for all types of services provided by the centre, and every year it undergoes a procedure for confirming the compliance of services with established requirements by independent organizations. [24]. 
The Medical Centre in FEFU also became one of the first university clinics in the Russian Federation; it was commissioned on July 1, 2013. In September, consultative polyclinics and a diagnostic department began their work, in November a surgery department and a hospital were opened. In April 2014, the first high-tech operation was carried out at the expense of the federal budget. The medical centre is a pilot project of the Russian Federation Government: for the first time, a medical organization is subordinate to the Ministry of Education, and not to the Ministry of Healthcare, and is part of FEFU. Equipped with unique equipment, the medical centre provides highly qualified diagnostic, advisory, medical and rehabilitation assistance. The main tasks of the centre are to provide specialized, including high-tech, medical services; to develop and implement modern diagnostic, treatment and rehabilitation techniques; to organize the conditions for biomedical technologies development, to continuously train the personnel; to create a clinical base that provides a high level of the educational process and meets the needs of practical medicine. More than 5,000 high-tech operations are carried out annually at the Medical Center of FEFU at the expense of the federal budget. The structure of the MC in FEFU includes an adult and children's polyclinic in order to provide expert advice. [25].

In early 2016, Kazan Federal University (KFU) has its own University clinic, which gave a powerful impetus to the development of clinical medicine and medical science in the region. Unlike MSEC in LMSU and MC in FEFU, whose activities are focused on hightech medical care, in the University Clinic of KFU, along with high technologies and scientific areas, they retained the entire system of providing assistance to the population within the framework of state guarantees. The University Clinic includes the collectives and property of state healthcare institutions RCH-2 (Regional Clinical Hospital-2), BSPM-2 (Emergency Hospital-2), formerly the 6th City hospital) and the 2nd District polyclinic. Together with the assets, the functions of parent organizations were transferred to the university. RCH-2 became a technological donor, which initially had more high-tech treatment methods. BSPM-2 traditionally specialized in surgical methods of treatment. The 2nd polyclinic covered the entire range of outpatient and polyclinic services plus preventive work with the population; about 40 thousand residents are assigned to the polyclinic. There was no such experience in organizing a medical cluster in Tatarstan. The university clinic gave a powerful impetus to developing clinical medicine and medical science in the region; the experiment in the medical education system became not only unique, but also successful. Currently, three main blocks have been formed: the cardiovascular department on the basis of the former RCH-2, the centre for surgical treatment methods at the BSPM and the outpatient clinic. The university conducts serious genetic research, the cardiovascular direction is relevant, including the application of cell technologies and minimally invasive methods of treatment. The main advantage lies in the very model of the clinic, which opens up the accessibility of the population to high-tech medical care: when the clinic includes a polyclinic service, the people assigned to it have the advantage of quick access to a wide range of high technologies. Among the indicators of deputy chief doctors' effectiveness of the clinic, there is also the number of patients who received hightech medical care during the reporting period. The inclusion of the University Clinic in KFU made it possible to remove restrictions in developing medical technologies. KFU has invested more than a billion rubles in the practical healthcare infrastructure, and the republic is also providing assistance in developing the medical cluster [26].

On the basis of the Medical Institute of IKBFU, in October 2012, the Clinical Diagnostic Centre (CDC) was established in Kaliningrad, whose tasks included the implementation of educational (educational practices, internships), clinical and research activities. The centre operates on the regional medical services market as a polyclinic medical organization, provides medical services to students and employees of IKBFU. as well as the services provision on the open market in the framework of the obligatory 
medical insurance system, voluntary health insurance, including fee-paying. The key activities of CDC: scientific and practical training of senior medical personnel and students of the Medical Institute of IKBFU; the development of innovative science-based approaches to the medical care provision; the medical services provision and medical services of a high level through modern diagnostic methods. The clinic has unique medical equipment purchased under the IKBFU Development Program, which makes it possible to perform biochemical, histological (including electronic microscopy), X-ray, ultrasonic and functional research methods. According to statistics (form 1-Zdrav), in 2019, 27,911 people attended CDC IKBFU, the average cost of the service provided varies from 722 rubles. up to 3288 rubles, the total amount of income from the provision of fee-paying medical services of CDC exceeded 2 million rubles. Eight years later in 2020, the IKBFU management made a decision to reposition CDC on the platform of the University Clinic brand with the aim of its sustainable development for the period 2020 - 2024, including improving financial results from the provision of fee-paying medical services.[27].

Thus, the analysis shows that all over the world the activities of university clinics are based on close interaction and coordination of educational, clinical and research activities. This allows us to train highly qualified medical specialists with modern theoretical knowledge and practical skills, as well as provide medical care using advanced technologies and the latest achievements of medical science. In addition, the formed image of University Clinics allows to have a steady influx of clients (patients) and the corresponding financial result from fee-paying services in their activities.

Despite some difference in approaches to the creation of university clinics in Russia, it can be concluded that today a new concept of university standards for the medical care provision is being formed. The main advantage lies in the model of the University Clinic itself - the quick accessibility of medical care to a wide range of medical services, including high-quality and high-tech medicine [28]. One of the main tasks of the University clinics is to strengthen communication between doctors and patients, as well as a wide coverage of the population prevention. In the changing environment associated with the pandemic, this challenge becomes even more urgent. It is the University clinics with scientific potential, highly qualified personnel, access to high technologies and educational skills that can become the basis for implementing, for example, "Volunteer programs" for testing vaccines, which has already been confirmed by the experience of some University clinics in the regions of the Russian Federation during the pandemic COVID-19, in particular in the Kaliningrad region.

Thus, we can conclude that the University Clinic is a fairly effective and promising model for developing clinical medicine in Russia. However, there are a number of problems, both organizational, managerial and methodological, hindering their development. Without pleading for the importance of solving specific medical problems, no less important are the issues related to budgeting and university clinics efficiency, their departmental affiliation, organizational structure and management, as well as their position in the unified system of Russian healthcare.

In the context of digital transformation, one of the problems in medical services provision is the population distrust and dissatisfaction with the quality of medical care. In order to form the necessary perception and raise the trust level in the domestic healthcare system, information openness, competent positioning of university medical centres, including the one on the platform of the University Clinic brand, are required. 


\subsection{Innovative approach to concept formation of medical centres positioning on the platform of "University Clinic" brand, ensuring information transparency}

The issues of brand positioning are given sufficient attention both in the scientific literature and in the practical activities of companies from various business areas [5, 6, 29]. However, the development of the concept of medical organizations positioning, such as the University Clinic on the principles of branding has not yet been the subject of full-fledged scientific research and discussion. A study of the practice of university medical centers positioning shows that the following two approaches to positioning university hospitals are most often applied. In the first case, the emphasis is made on the fact that the University Clinic is a "Clinic of a complex case", focusing on the special status of this medical organization. Secondly, "The University Clinic is a wide-profile clinic, equipped with modern high-tech equipment and with highly qualified medical personnel. Both approaches are interconnected and justified, but it is necessary to understand what the placement of accents and the choice of the final version of the positioning concept depends on, since this subsequently affects a number of indicators, including the financial result of the University Clinic activities and its effectiveness indicators. The main factor influencing the choice of the positioning concept is the mechanism and possibilities of its budgeting. A university clinic can be positioned as a "Clinic of a complex case" if it has approved volumes of the state guaranteed order for medical services, which should not be reduced. For example, the University Clinic of KFU is now working according to this model, which gave a powerful impetus to the clinical medicine development and medical science in the region, and this experiment in the medical education system has become very successful. If the main part of the University Clinic budget is formed through the provision of fee-paying medical services, then the second approach to positioning is preferable, since the concept of the "Clinic of a complex case" will narrow the target audience in terms of paying capacity level, will not allow a wide coverage of the population with standard treatment methods, and accessibility for them, including high-tech medical care.

In June 2020, the management of IKBFU decided to reposition CDC on the platform of the "University Clinic" brand with the aim of its sustainable development and achievement of the strategic goals for the period 2020 - 2024, including improving financial results from the fee-paying medical services provision. For this purpose, a study of the market of medical services in the region was carried out, an assessment of the competitive position of CDC was made, the media policy of CDC was analyzed, the surveys of the population and medical personnel in the region were conducted in order to assess its activities, the recognition degree of $\mathrm{CDC}$, satisfaction with the quality of medical services provided and their availability to the population, the positions and media strategies of the main medical organizations in the Russian Federation and the region were analyzed. Since in the digital economy and information openness the choice of a medical organization is largely made on the basis of information from the Internet, the study analyzed extended reviews on the largest and most authoritative portals, including ProDoctors, Yandex, Google, the websites of medical centres, advertising materials online and offline, mentioning the clinics in federal and international ratings by analytical centres and consulting organizations. [30, 31] The presence of these medical centers in social networks, their advertising materials, as well as work with reviews were analyzed in detail.

From the methodological point of view, when forming the positioning concept of the medical center on the platform of the "University Clinic" brand, it is important to analyze what image has been developed among the patients at the moment since the concepts "desired image" and "current (actually formed) image" quite often do not coincide. The field research (questionnaire survey) aimed at assessing the perception of the brand of CDC IKBFU, covering two target audiences, doctors representing the opinion of the medical 
community of the region, and real and potential patients of the clinic, conducted in JuneAugust 2020, led to the following results. According to the doctors, the CDC IKBFU should be associated with a clinic that provides high-quality routine medical care based on both standard and high-tech methods, while they believe that at the moment the Centre is not perceived either as a "general clinic" or as a "clinic of a complex case" (24\%). A survey of the population of the region showed that the brand awareness of $\mathrm{CDC}$ as the clinic of IKBFU is high (59.3\%); however, there is no clear association with specific services and benefits provided in CDC, there is no stable perception of how CDC differs from other polyclinic medical organizations in the region $(63,6 \%)$. The study identified the following main problems directly related to the positioning and promoting CDC IKBFU:

- with a sufficiently high recognition of CDC as a clinic of IKBFU, the positioning of the "University Clinic" brand, its values and the advantages provided are not formed;

- weak association of the CDC brand with specific medical services provided by CDC, locomotive services are not highlighted and not promoted properly;

- there is no stable association of the CDC brand with the main customer value of the medical centre - the medical services quality provided;

- there is no information about the uniqueness of the available medical equipment, its purpose, in a form understandable to patients, neither posted on the website, nor in printed information materials;

- The main reason for the low attendance of CDC is the lack of a competent media policy, insufficient application of modern digital technologies and innovative tools, both in the offline environment and, most importantly, in the online environment. Information about CDC is posted on the information portals, but active work is not conducted on them; on the largest medical portal in Russia, ProDoctors, the CDC IKBFU rating is 0.69.

- there are no interactive online functions on the CDC website: consultations with specialists, filing a complaint, electronic registration, FAQ section (answers to frequently asked questions), opportunities to give feedback, patients' forums, opportunities to make a comment, maintaining a corporate blog, a questionnaire on satisfaction with quality;

- there is a problem of making an appointment with a doctor online; statistics of initial and repeated visits to $\mathrm{CDC}$ are not kept, which does not make it possible to effectively manage the client base of the clinic's visitors;

- working hours do not include evening and weekend work; in the waiting areas, information materials that contribute to the formation of demand for the services of CDC are not presented, there is no wifi access;

Despite the fact that this list concerns a specific object of research, information analysis on the University clinics positioning shows that it is quite typical and reflects the main problems and shortcomings in the positioning concept and its implementation in practice for most medical organizations of this type.

The relevance of the University clinics positioning, including CDC, is increasing due to the fact that in conditions of fierce competition and the expanding influence of the digital environment, there is a shift from "competition of goods" towards "competition of their perception by consumers". The purpose of positioning is, through promotion tools, on the one hand, to maximally join the values of its target audience (the values of their patients), and on the other, to maximally distance themselves from existing competing clinics [32]. Competent positioning will allow to form the desired perception of the University Clinic among the target audience, increase its recognition, make an effective campaign to promote the brand of the clinic and its services, and, as a result, increase ce the University Clinic attendance, which leads, among other things, to an increase in financial results from its activities, an increase in revenue and profit. In order to achieve the desired perception of the "University Clinic" brand among the target audience, it is necessary to conduct a competitive analysis of the main players positioning in the regional medical services 
market. The medical clinics and centres of the region are positioned in different ways according to various attributes: according to the medical profile and areas of activity, convenience of location, proximity to clients; the quality of medical services; the owners' names or famous chief doctors; family and consumer values; innovative medical technologies, etc. [33]. In order to develop proposals for the CDC positioning, the main clinics in the region, presented on the largest and most authoritative portals, including ProDoctors, Zoon, Yandex, Google, 2GIS, were analyzed and site analytics was carried out. The Clinical and Diagnostic Centre of Immanuel Kant Baltic Federal University is currently positioned as a multidisciplinary clinic that provides a range of medical services with a focus on functional diagnostics, affiliation to IKBFU being highlighted. In order to assess the current positioning, the analysis of the CDC website was carried out with application of the online analytics service of the SimilarWeb website. (Table 4).

Table 4. Results of site med.kantiana analytics.

\begin{tabular}{|l|l|}
\hline \multicolumn{1}{|c|}{ Indicator name } & \multicolumn{1}{c|}{ Indicator value } \\
\hline Position in Yandex on request "Medical Clinic Kaliningrad" & 47 \\
\hline Position in Google on request "Medical Clinic Kaliningrad" & $\begin{array}{l}\text { not included in the top } 100 \text { in } \\
\text { the search results }\end{array}$ \\
\hline Number of site visits per month & less than 5000 \\
\hline Number of visits in the last 3 months & less than 5000 \\
\hline Number of unique visitors per month & less than 5000 \\
\hline Average website visit time (minutes) & $01: 16$ \\
\hline Average number of pages visited & 2,06 \\
\hline Main traffic sources & $\begin{array}{l}\text { Organic search }-70,76 \% \\
\text { Direct transition } 26,08 \% \\
\text { Referral links (2GIS) }-3,16 \%\end{array}$ \\
\hline Traffic share of computer (C) and mobile (M) versions & $\begin{array}{l}\mathrm{K}-25,57 \% \\
\mathrm{M}-74,43 \%\end{array}$ \\
\hline $\begin{array}{l}\text { Bounce rate (\%) - the percentage of the number of visitors } \\
\text { who left the site directly from the login page or viewed no } \\
\text { more than one page of the site }\end{array}$ & $40,26 \%$ \\
\hline
\end{tabular}

The results obtained on the site med.kantiana.ru presents that users do not stay on the site: $40 \%$ of those who entered the site soon left it. The lack of an SEO strategy has led to the fact that the site does not appear on the first pages in Yandex in the search results, and in Google it does not even enter the top 100 by request. At the same time, $74.43 \%$ of those who visited the website of the centre used the mobile version, and $25.57 \%$ used the full version of the website. On average, a user spends 1 minute 16 seconds visiting the company's website and finding the information they require. During this time, the average user visits two pages on the site.

Thus, based on the analysis results, it was concluded that the positioning of the CDC is not focused on its competitive advantages, is not focused on an external target audience and does not allow other 67 regional competing clinics to move away from positioning.

After conducting a strategic analysis of the medical services market and assessing the competitive position of the medical centre, it is necessary to further formulate the essence of the concept of brand positioning on the University Clinic platform, its main values, determine the main channels and tools for broadcasting these values to the target audience in the information environment. For these purposes, the brand value pyramid model can be used. [five].

The concept of positioning and the strategy of promotion on the platform of the "University Clinic" brand should be built on the maximum distance from competitors, promoting the unique advantages of the clinic, actively forming the image of the clinic as a leader in the regional market, breaking negative stereotypes that "high-quality and 
affordable medicine" can be only be provided in the capital and foreign clinics. It is advisable to make a bet on the connection with the university, classical, but at the same time modern medicine. This approach will allow you to favorably distinguish from competitors and stand out in the general, monotonous advertising field of medical centres operating in the region, to form the desired image of a "different clinic" offering a "new quality of life" based on the positions of evidence-based medicine and an individual approach, as well as a high level of service. ...

For CDC IKBFU, according to the research findings, the essence of the new concept of positioning (brand essence) was formulated as follows - "University clinic - a professional approach to your health problems!" The purpose of positioning CDC on the platform of the "University Clinic" brand is to form a stable association and perception among the residents of the region that a "University Clinic" exists in the region, which has the opportunity, applying the scientific potential and resources of the Federal University, to provide unique medical products and services based on high-tech methods of diagnostics and treatment, innovative biotechnology and medical technologies, professionalism of doctors who are able to solve complex problems of clients spontaneously, without leaving the region.

An innovative approach to the positioning concept of CDC on the platform of the "University Clinic" brand can be expressed with the following model (Fig. 2) "Brand values pyramid ":

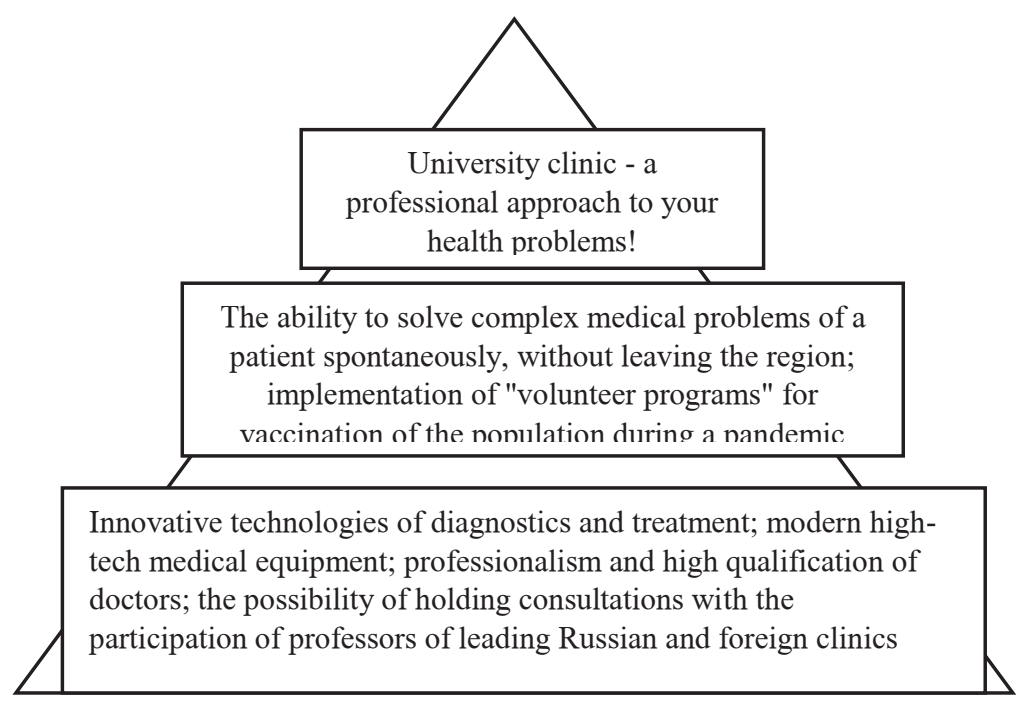

Fig. 2. Brand Values Pyramid of "University Clinic"

Methodologically, the Brand Values Pyramid is built in such a way that its upper level expresses the essence of the University Clinic brand, the second level conveys the benefits that the population of the region can obtain from interacting with the clinic, and the lower level specifies and shows on the basis of what and why the clinic can deliver these benefits and values to clients. The proposed Brand Values Pyramid of the "University Clinic" brand meets the basic values of the target audience and is the basis of the entire media policy of the clinic, ensuring its information transparency. In the value system of the "University Clinic" brand pyramid, it is also important to reflect the possibility of implementing "volunteer programs" to vaccinate the population during a pandemic, which is very important in connection with the emerging epidemiological situation and future trends.

When implementing the chosen positioning concept of the University Clinic, it is necessary to apply modern technologies and digital marketing tools: placement on specialized medical portals, work in social networks, the introduction of chat bots that 
allow to be in touch with clients $24 / 7$, and others. [34]. In order to promote in search engines, it is recommended to use SEO-optimization of sites and search advertising, which increases the flow of potential patients to the site, to actively apply the services "Google AdWords" and "Yandex.Direct". [35]

Since in the digital economy and the situation of information openness a consumer's choice is complicated by information asymmetry: distrust of classical advertising channels used by medical institutions, focusing on the opinions of friends and acquaintances with experience in obtaining medical services through social networks and reviews on medical portals, it is necessary to correctly build the implementation of the positioning concept on the platform of the "University Clinic" brand in the online environment. With regard to CDC IKBFU, which is the subject of the study, the following recommendations were made as the main recommendations for implementing the proposed positioning concept on the platform of the "University Clinic" brand:

- SEO strategy development and website updating. A procedure for reorganizing the site is proposed, including a description of the new structure of the site, the main tools for Internet promotion, examples of design layouts for all the main sections and pages of the CDC "University Clinic" site;

- implementation of Internet analytics: the need to use such web analytics services as GoogleAnalytics and Yandex.Metrica, which will allow to receive detailed information about the audience of the site, as well as get a detailed analysis of the effectiveness of each element on the site and the entire resource as a whole;

- activation of work in social networks: the creation of official accounts of CDC, the maintenance of pages in the most popular social networks (Vkontakte, YouTube, Facebook and Instagram) and professional portals and forums related to medicine, which will increase traffic and the involvement of potential clients; the degree of brand awareness of the "University Clinic" brand; building trust in the clinic;

-creation and filling of "profiles" of doctors on large portals (prodoctorov.ru, med39.ru, kaliningrad.zoon.ru): a doctor's photo, work experience, qualifications, what services they provide, opening hours, how to make an appointment. Timely creation and updating of doctors' personal pages in social networks is necessary: updating doctors' "avatars", creating a relevant profile description;

-working with customer reviews; blogging on the clinic's website, where doctors can publish useful articles on their specialization, share experiences and give advice, both in interview format and in the an author's column format;

-changing the standards of patient service and adjusting business processes related primarily to the work of the reception (the ability to make an appointment online through social networks, Vkontakte, Facebook and Instagram and online chats: WhatsApp and Telegram) and managing the customer database, which should be based on modern information technologies, i.e. CRM - systems, Bitrix-24 and others;

- organization of e-mailing for a segmented target audience based on the CRM-system, which will increase repeated calls;

- the need to attract third-party specialists who are primarily involved in customer database management and marketing, in particular, an SMM specialist responsible for the published content, professional copywriters, photographers;

- a budget was calculated and a media plan (Gantt chart) was developed for the period from August 2020 to August 2021. The budget is calculated on the basis of a full-fledged programme for promoting the clinic brand in the online and offline environment, based on the prevailing average market prices on advertising and branding and is $7.5 \%$ of the clinic revenue from fee-paying medical services, which is quite an acceptable indicator. 


\section{Conclusions}

- Based on the study of the experience of leading foreign and Russian University clinics, it can be concluded that University clinics, as medical organizations of a special status, are a very promising model for providing medical services to the population in terms of changing challenges. The creation and development of a University clinics network on the basis of federal universities in a number of regions of the country (Kazan, Yekaterinburg, Novosibirsk, Kaliningrad, Rostov, Vladivostok, etc.) will make high-tech services to the population in these regions more accessible and will contribute to achieving the goals of sustainable economic development, since university clinics can be the core for creating medical clusters in these regions.

- Modern challenges require an innovative approach to the positioning of University clinics. Competent positioning of medical centres on the platform of the "University Clinic" brand has not only economic, but also social effect, since it contributes to a change in the behavior of the population in relation to their health, the possibilities of domestic medicine, the growth of trust and access to high-quality and high-tech medical care in the regions. will form the image of a "different clinic" offering a "new quality of life" based on the positions of evidence-based medicine and an individual approach. In addition, University clinics can be the basis for implementing "volunteer programs" for testing vaccines, which is very important in connection with the emerging epidemiological situation and trends for the future.

- In the context of digital transformation, the implementation of an innovative approach to positioning should be based on the basic principles of brand management and is not possible without the introduction of appropriate digital technologies and tools in the process of positioning and promoting the "University Clinic" brand, as shown by the authors' study using the example of CDC IKBFU in Kaliningrad.

- The issue of solving the problems of the university medicine development, including the University clinics network in the Russian Federation, is much broader and is not limited to the range of problems proposed by the authors in this article, it presupposes a more complete discussion of a whole range of issues of both scientific, methodological and practical nature concerning organizational, managerial and legislative aspects related to their departmental subordination, work coordination of the ministries of education and health, sources of their funding, forms of state support and others, which will be the subject of subsequent research of the authors.

\section{References}

1. On national development goals of the Russian Federation for the period up to 2030. Decree of the President of the Russian Federation of July 21, 2020 No. 474, http://kremlin.ru/

2. Transforming Our World: The 2030 Agenda for Sustainable Development. UN General Assembly Resolution, A / RES / 70/1

3. European Commission. EU Approach to sustainable development, https://ec.europa.eu

4. N. Afanasyeva, The history of university clinics as a path to the development of medical science (Federal News Agency, 2012) https://ria.ru /

5. D. Aaker, E. Jochimstayler, Brand Leadership: A New Concept (2003)

6. K. Dinny, Territory branding. The world's best practices (2013)

7. A. Raszkowski, E. Sobczak, The 13th International Days of Statistics and Economics, 1253 (Prague, Czech Republic, 2019) 
8. S. Grönholm, L. Rydén, O. Zui, C. Elrick-Barr, N. Powell, Assessing the Status of Sustainable Development in the Baltic Sea Region: A Macro-regional Perspective (Baltic University Program Press, Uppsala, 2015)

9. Official site of the Federal State Statistics Service, https //rosstat.gov.ru

10. Official site of the Ministry of Health of the Russian Federation, https://minzdrav.gov.ru

11. BusinesStat: Analysis of the medical services market in Russia in 2016-2020, assessment of the impact of coronavirus and forecast for 2021-2025, https://businesstat.ru

12. Market research of private medicine (2020) https://marketing.rbc.ru

13. Official website of the Ministry of Health of the Kaliningrad Region, https://Infomed39.ru

14. N. E. Kubina., D. P. Belenkov, Marketing in Russia and abroad, 2, 90 (2021)

15. University Medical Complex "Charité" (Charité) in Berlin, https://bookinghealth.ru

16. University Hospital Grenoble Alpes (CHUGA), https://www.univ-grenoble-alpes.fr

17. University hospitals in the UK (University Hospitals or Teaching Hospitals https://universityhospitals.org.uk

18. Association of American Medical Schools (Council of Teaching Hospitals and Health Systems, COTH) https://aamc.org

19. Hadassah Clinic (Jerusalem Jewish University Clinic) https://hadassah.ru

20. Medical Center "Soroka" at the University. Ben-Gurion in the Negev, https://sorokahospital.com

21. Vilnius University Hospital "Santariškių klinikos”, http://www.olitve.ru

22. Medical Center Tartu University Clinic https://kliinikum.ee/404-2/

23. Medical Research and Education Center of Lomonosov Moscow State University, http://mc.msu.ru

24. Clinic of high medical technologies of St. Petersburg State University, https://spbu.ru/universitet/klinika-spbgu

25. FEFU Medical Center, https://dvfu.ru

26. Kazan Federal University. University clinic. https://uniclinic.kpfu.ru

27. Immanuel Kant Baltic Federal University. Clinical Diagnostic Center (CDC) https://kantiana.ru

28. I. Krasnopolskaya. University clinics are reviving in Russia. // Rossiyskaya Gazeta, No. 6923 (2016)

29. T. Yu. Bykovskaya, A. V. Panov, Medical Council, 21, 231, (2018)

30. Association of Communication Agencies of Russia, https://akarussia.ru

31. International consulting company "J'son \& Partners Consulting", https://json.ru

32. Al Rice, Jack Trout, Positioning. Battle for Minds (2015)

33. R. A. Khalfin, Bulletin of the Peoples' Friendship University of Russia. Series: Medicine, 23(1), 104 (2019)

34. O. V. Khodakova, Yu. V. Evstafiev, Healthcare of the Russian Federation, 61(2), 70, (2017)

35. I. M. Sinyaeva, Business strategies, 6, 19 (2019) 